\title{
Sevilla: a successful experience of bicycle promotion in a Mediterranean context
}

\author{
R. Marqués ${ }^{1}$, V. Hernández-Herrador ${ }^{1} \&$ M. Calvo-Salazar ${ }^{2}$ \\ ${ }^{1}$ SIBUS, University of Sevilla, Spain \\ ${ }^{2}$ Estudio MC, Spain
}

\begin{abstract}
From 2006 to 2011 Sevilla experienced a rapid growth in urban cycling, from a negligible participation in the modal split up to $9 \%$ of the total mechanical trips. This rapid growth was based on some active policies heavily based on the building of a continuous and homogeneous network of segregated cycle paths. In this paper we analyse the main guidelines for the development of this infrastructure, as well as its impact on urban mobility and bicycle traffic safety. We found that the risk of cycling was reduced in parallel to the increase in the number of cyclists, in agreement with the safety in numbers hypothesis. Future trends for further improving bike mobility are also described and analysed. Finally, we make an estimation of the possible effects on bicycle use of a hypothetical compulsory helmet regulation, a possibility that is presently under debate in Spain.
\end{abstract}

Keywords: bicycling, active mobility, cycleways, public bikes, sustainable transport, Sevilla (Seville), Spain, Mediterranean region.

\section{Introduction}

Growing public awareness about the negative impacts of car-based urban mobility on the environment and public health has pushed up for the search of soft urban mobility alternatives, such as bicycling $[1,2]$. A meaningful presence of cycling in the modal split is common in many cities of Central and Northern Europe, as well as in China and Japan [2-6]. However, in Mediterranean Countries, utilitarian cycling has only reached meaningful levels in a few number of cities. In spite of its low tradition of cycling, Sevilla has probably been one of the more successful Mediterranean cities in the promotion of bicycling [7]. In just five years (from 2006 to 2011) utilitarian cycling in Sevilla increased from negligible levels to 
meaningful values of the modal split $[8,15]$. This contribution is aimed to describe and analyse this process, its impact on city mobility and bicycle traffic safety, and the future trends for further developing bicycle mobility. Our work ends with an estimation of the possible effects on bicycle use of compulsory helmets, something that is presently under debate in Spain.

\section{Development of the infrastructure}

Sevilla is a typical high density Mediterranean city of 702.000 inhabitants, surrounded by a low density conurbation with approximately the same population. The per-capita gross domestic product is of 18,600 €/hab-year and the percent of car-free households is around $20 \%$ in the whole Metropolitan Region. Its flat terrain and dry weather favour cycling, except in summer, when temperatures become very high. However, the absence of any cycling infrastructure prevented the development of utilitarian cycling until very recently, when the percentage of bicycle trips rose above a $5 \%$ of the modal split.

Meaningful percentages of cycling are common in medium and small cities in Northern Italy, such as Ferrara (27\%, 135,000 inhabitants), Padua (16\%, 206,000 inhabitants) or Venezia (7\%, 289,000 inhabitants) among others [9]. Other Mediterranean cities above 100.000 inhabitants with percentages of cycling above $5 \%$ are Skhoder $(29 \%, 110.000$ inhabitants) in Albania, and Thessaloniki $(10 \%$, 780,000 inhabitants) in Greece [9]. Bordeaux and Toulouse, in the South of France, also show significant levels of cycling [7, 9]. However, which makes special the case of Sevilla is the rapid growth of utilitarian cycling, from negligible values to a significant percentage of the modal split in just five years [7]. The 1983 mobility survey found a $2 \%$ of total trips made by bike; that proportion did fall to a $0.6 \%$ in 1991 , and to negligible amounts in subsequent mobility studies. However, in November 2011, just five years after the construction of the cycle network began, a $5.6 \%$ of bicycle trips ( $9 \%$ of all mechanical trips) was reported in the city.

As mentioned above, the construction of the cycling infrastructure began in 2006. In 2007 the City Council approved the Bike Masterplan, which defined a cycle network of $120 \mathrm{~km}$, as well as other measures for promoting cycling. A map of the cycle network developed between 2006 and 2010 is shown in Fig. 1. Further developments increased the length of this network until $164 \mathrm{~km}$ in 2013 [10].

The main guidelines for the cycle network design were [8]:

1) Segregation: The whole network was segregated from motorised traffic.

2) Connectivity: The network was designed to connect the main trip attractors with the main residential areas.

3) Continuity: All bike paths make a continuous network without gaps along it.

4) Homogeneity: All the cycleways share a uniform pavement and design.

5) Bi-directionality: Almost all cycleways are bi-directional.

Quick building: A basic network was built in just two years, and after 5 years, i.e. between 2006 and 2010, most important cycleways were finished (see Figure 1). 


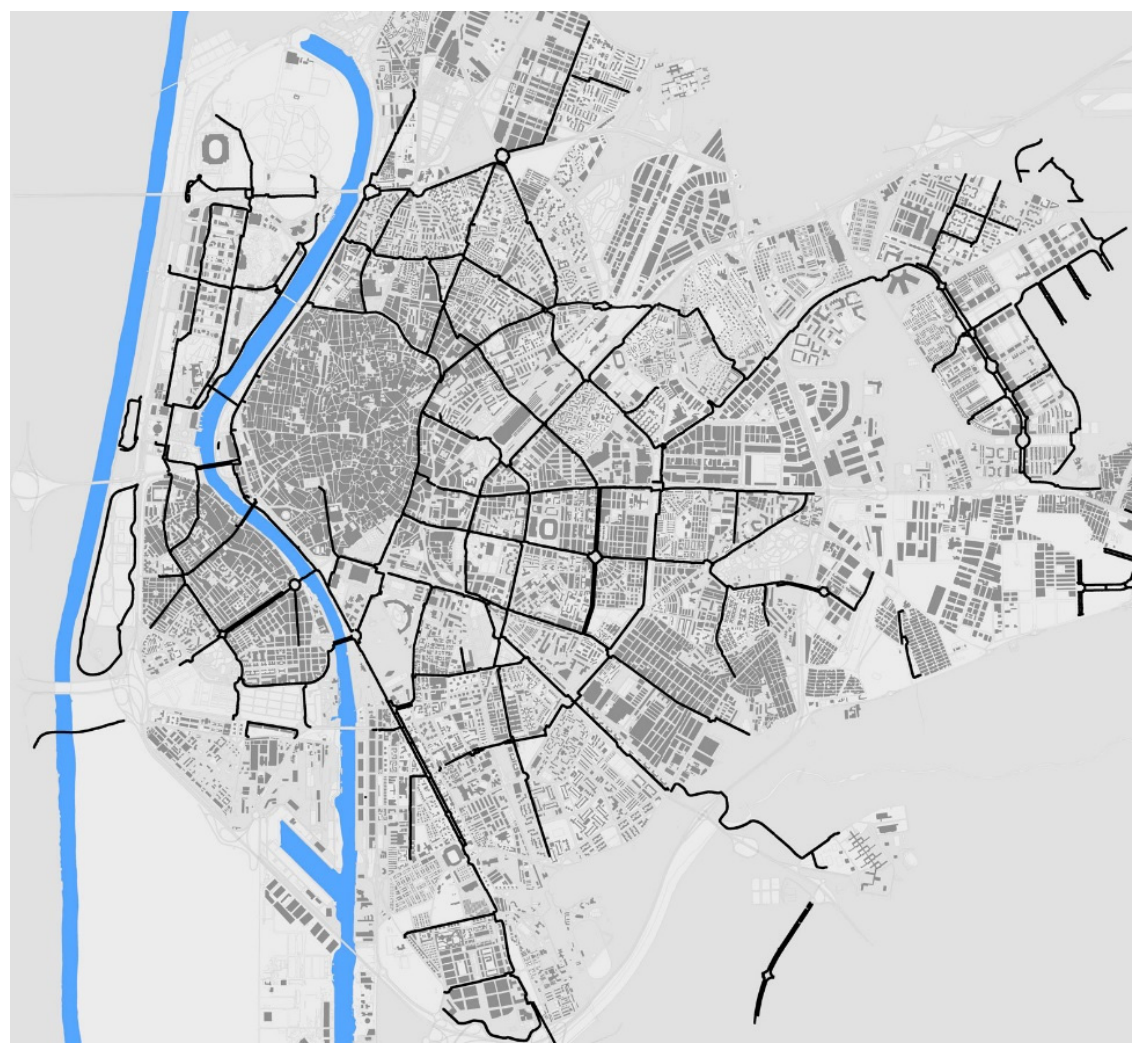

Figure 1: Map of the cycle network in 2010.

Characteristics 1 to 4 were intended to make cycling not just safe but also easy and comfortable (or even "irresistible" [3]) for everybody: The segregation from motorised traffic improves both the safety as the feeling of safety. The network connectivity makes it useful for everyday use, and the network continuity makes bicycle trips obstacle-free and comfortable. Homogeneity is important in order to make the network recognizable for occasional cyclists, makes it attractive for beginners and easier to use in intersections. In general, the bicycle network was designed thinking more on the needs of potential cyclists than on the needs of actual cyclists.

Most cycle paths were 2.5 meters width bi-directional cycleways. The main reason for this choice was that, in a city with few tradition of cycling, it was expected that many cyclists will ride counterflow if the bike-paths were made mono-directional. Moreover, a bi-directional cycle path is easier to design and build than the alternative of a pair of two mono-directional cycleways. A 2.5 meters width bi-directional cycleway also saves space with regard to two 1.5 meters width mono-directional cycleways, something that can be important in 
dense cities like Sevilla. Finally, if bicycle traffic grows above the capacity of a bi-directional cycleway, building its counterpart at the opposite side of the street - as it is presently done in many Dutch cities - can be an easy solution.

All cycleways shared a uniform pavement, green coloured. Most of them were built over previously existing parking lanes, which were eliminated (alternatively, traffic lanes were narrowed or eliminated). Cycleways were predominantly located between the pedestrian area and the carriageway and, if the parking lane persisted after the building of the cycleway, a space of $50 \mathrm{~cm}$ was usually left between the parking lane and the cycleway, in order to prevent dooring. Very often the cycleways were built at the same level as the pedestrian area, in order to further enhance the feeling of safety by bicyclists. This building technique was controversial, giving rise to conflicts with neighbours (who lost parking spaces) and pedestrians, who interpreted that the cycleways were built on the sidewalks [8]. Figure 2 shows an example of the transformation of a typical street of the central area of the city after the building of a cycleway.

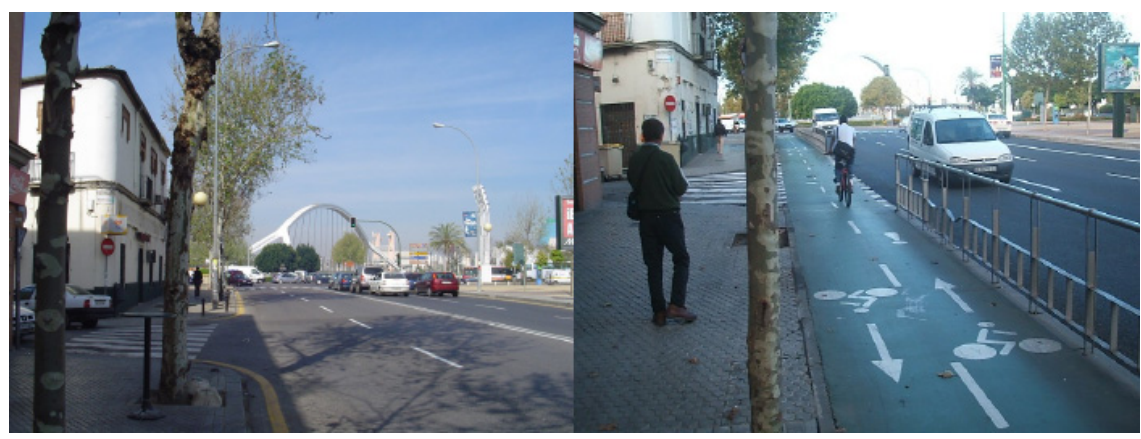

Figure 2: A typical street before and after the implementation of a bike path.

Sometimes, the bike paths shared space with pedestrians, which always have priority in such cases. This kind of shared paths have the same pavement than the surrounding pedestrian areas, and are delimited by small metallic studs. Moreover, bicyclists are allowed to ride on wide pedestrian areas (more than 5 meters width) at small velocities (less than $10 \mathrm{~km} / \mathrm{h}$ ) and giving priority to pedestrians. These determinations have been controversial, even leading to lawsuits that reached the Supreme Court, which ultimately upheld the City Council. This example gives an idea on the difficulties that the building of the cycling infrastructure had to face in a very conservative and ancient city, with almost no tradition of urban cycling, like Sevilla.

Regarding the historical centre, as it can be seen in Fig. 1, there are no cycle paths on it. The structure of this space, plenty of narrow and calm streets, makes it much more suitable for traffic calming than for cycle paths building. The only bike path on this area is a shared lane with pedestrians, parallel to a tram line running along the main pedestrian avenue. 
Efforts were made in order to build the whole network in a short period of time. This decision was taken in order to improve the perception of usefulness of the cycle network from the outset. Monetary costs of the cycle-network can be estimated in $270,000 €$ per $\mathrm{km}$ [8], with a maintenance costs of 1,500 € per km and year. These costs are higher than the cost of other alternatives, such as bikelanes directly painted on the carriageway. However, they are still much smaller than the costs of motorised traffic infrastructure, including motorised public transport [8].

The bike paths were combined with more than 5,000 parking places on the streets, located near the main trip attractors such as schools, workplaces, commercial areas, public transport hubs, parks, etc. [8]. Closed parking at home, as well as inside public transport stations, educational centres, workplaces and commercial areas is an important part of bike infrastructure (see, for instance, [11]). Some communities allow residents park their bicycles in common areas, but others do not accept bicycles, or even prohibit them, which is a clear drawback for bicycle promotion.

Bicycles are usually allowed, with restrictions, in urban and subway trains. However, there are not parking facilities inside public transport stations, except at a single bus-station, which is the main metropolitan bus station, where there is also a one-day bicycle loan service [8] - similar to the Dutch OV-fiets. For this reason, the use of the bike in combination with the public transport is usually made by transporting the bike on board (see next section).

Parking facilities in closed areas are provided at the university buildings. The University of Sevilla has around 70.000 members, a $10 \%$ of the city population. Its buildings are spread across the city and most of them are equipped with closed bike parking areas restricted to the university people. The University also offers a long term (one academic year) bike loan service to its members [12]. The situation in primary and secondary schools is quite uneven. Some of them promote bicycling among the students and offer bike parking areas inside the school. Others, however, do not allow bicycles inside or do not offer an appropriate parking infrastructure. As a consequence, the use of the bicycle to go to the school varies a lot from one school to another. Something similar happens with working places and shopping centres. In general, shopping centres and working places are best equipped for car parking than for bike parking. Therefore, except at the University, infrastructure for bike parking at most trip attractors is not well developed in the city. This is another apparent bottleneck for a further expansion of bicycle mobility.

In 2007, shortly after the first cycleways were made, a public bike sharing system was launched in exchange for advertising spaces on the street furniture $[8,13]$. The success was immediate, reaching a maximum of 59,455 associates in December 2009, two years and four months after the system started [13]. At such time, the system became almost saturated, with peaks of more than 10 uses per bike and day $[13,14]$. Presently, the system has 2,650 bikes in 260 stations, and is stabilized with a number of associates slightly below 45.000 and 6 to 7 uses per bicycle in a typical business day [13]. 


\section{Impact on mobility and bicycle traffic safety}

Consecutive counts of cyclists made on typical business days on representative points along the cycle network showed a fast growth of utilitarian cycling in the city $[8,15,19]$. The total number of cyclists detected in each count, however, depends on the number and the location of the observation points, and is not an effective indicator. A much better indicator is the average number of cyclists (ANC) detected per observation point. The evolution of this indicator is shown in the first row of Table 1. The data on Table 1 suggest that the bicycle use increased by a factor of approximately 6 in the period 2006-2011.

Table 1: Average Number of Cyclists (ANC) per observation point in the different counts of cyclists. Number of registered accidents per year, and ratio Accidents/ANC each year. Table compiled by the authors from data provided by the Ayuntamiento de Sevilla, by the Dirección General de Tráfico (DGT) and by author's research.

\begin{tabular}{|l|r|r|r|r|r|}
\hline & \multicolumn{1}{|c|}{$\begin{array}{c}2006 \\
\text { (Sept.) }\end{array}$} & \multicolumn{1}{c|}{$\begin{array}{c}2007 \\
\text { (July) }\end{array}$} & $\begin{array}{c}\text { 2008 } \\
\text { (May) }\end{array}$ & \multicolumn{1}{c|}{$\begin{array}{c}2009 \\
\text { (Nov.) }\end{array}$} & \multicolumn{1}{c|}{$\begin{array}{c}\text { (Nov.) } \\
\text { (Nov1 }\end{array}$} \\
\hline ANC & 330 & 532 & 1057 & 1587 & 1935 \\
\hline Accidents & 56 & 56 & 86 & 146 & 93 \\
\hline Accidents/ANC & 0.17 & 0.11 & 0.08 & 0.09 & 0.05 \\
\hline
\end{tabular}

Successive counts of cyclists along the cycle network can give an idea about the evolution of bicycle use, but they cannot give a reliable estimate of the actual number of bicycle trips. To make such an estimate an independent measure of another magnitude is needed with a known relationship to the number of bicycle trips. This magnitude can be the total number of trips made on public bikes, which is known daily by the operator. The percent of trips made on public bikes over the total number of bicycle trips can be measured during the count, thus giving an indirect but reliable measure of the daily number of bicycle trips. This strategy was applied by the authors during the last count of Table 1 (November 2011). The measured percent of trips on public bikes over the total was $28.77 \%$. From this result, and from the known number of trips detected by the public bike system, the total number of bicycle trips on a typical business day was evaluated in 72,565 [15].

The impact of this growth of utilitarian cycling on the modal split has been estimated using the data of the 2007 mobility survey [16], corrected in order to take into account the evolution in city mobility. Correction to the total number of trips by car was estimated from the known decline of traffic density along the city (16\% from 2007 to $2011[15,17])$. Correction to the total number of trips in public transport was estimated from data provided by the public transport companies [15]. The estimated modal split for mechanical trips is shown in the last row of Table 2. The evolution of the total number of walking trips is more difficult to 
estimate. If we assume that the total number of such trips has not varied substantially from 2007 to 2014, the results of this approximation for the modal split of all modes are also shown in Table 2 (figures in parentheses).

Table 2: $\quad$ Evolution of the city modal split of mechanical trips and of all kind of trips (figures in parentheses). Table compiled by the authors from data coming from the mobility surveys of 1990 [18] and 2007 [16], Municipality of Sevilla [19] and our own work [15]. Results for 2009 and 2011 are estimations.

\begin{tabular}{|l|c|c|r|c|c|}
\hline & Walk & Bicycle & Public Transport & Car & Motorbike \\
\hline 1990 & $--(46.7) \%$ & $1.1(0.6) \%$ & $46.0(24.5) \%$ & $46.7(24.9) \%$ & $6.2(3.3) \%$ \\
\hline 2007 & $--(36.5) \%$ & $5.0(3.2) \%$ & $30.7(19.5) \%$ & $57.2(36.3) \%$ & $7.1(4.5) \%$ \\
\hline 2009 & $--(37.1) \%$ & $6.6(4.1) \%$ & $32.5(20.5) \%$ & $52.8(33.2) \%$ & $8.1(5.1) \%$ \\
\hline 2011 & $--(36.7) \%$ & $8.9(5.6) \%$ & $34.8(22.2) \%$ & $48.3(30.5) \%$ & $8.0(5.0) \%$ \\
\hline
\end{tabular}

For the sake of completeness, previous results for the modal split coming from different sources are also shown in Table 2. The first row shows the modal split reported by the mobility survey of 1990 (the last one reporting results for bike mobility before 2007). The second row shows the results of the 2007 mobility survey. The third row shows the modal split in 2009 as estimated by the Municipality of Sevilla [19]. Finally, the fourth row shows the results of our estimations for 2011. A subsequent analysis developed by the authors two years later [20], suggests that these last figures were stabilized during the period 2011-2013. In spite of the different sources and methodologies, results of Table 2 show a very coherent evolution of the modal split in the city. Apart from the reported increase in cycling mobility, the most salient features are the decrease in car mobility and the increase of public transport trips in the period 2007-2011.

A survey was conducted in 2011 among a sample of 675 cyclists simultaneously to the last count [15]. The results of this survey gives information about the modal shift associated to the growing of urban cycling. These results are summarized in the first row of Table 3 . The last row gives the results of a previous survey developed in 2009. As it can be seen in the Table, there is a good qualitative agreement between both sources. The modal shift from car to bike is meaningful, but this alone cannot explain the estimated reduction in car mobility shown in Table 2. Other reasons, such as the economic crisis or the onset of new public transport infrastructures (subway and tram), could contribute to this decline.

Regarding the impact on traffic safety, the second row of Table 1 shows the yearly number of bicycle traffic accidents in the city of Sevilla. This figure has growth since 2006. However, the ratio between the total number of accidents and the average number of cyclists (ANC) shows a steady decline along years suggesting a meaningful decline in the risk of cycling. This decline is associated with an increase in the number of cyclists, in agreement with the "safety in numbers" hypothesis [21, 22]. 
Table 3: Modal shift for the new bicycle users as revealed by the surveys realized in 2011 [15] and 2009 [19]. Car trips include taxi and car passenger.

\begin{tabular}{|l|c|c|c|c|}
\hline & Walking & Public Transport & Car & Motorbike \\
\hline 201 & $28 \%$ & $40 \%$ & $28 \%$ & $4 \%$ \\
\hline 200 & $26 \%$ & $38 \%$ & $32 \%$ & $5 \%$ \\
\hline
\end{tabular}

Regarding vehicles involved in bicycle accidents, motorised vehicles were involved in a $77.2 \%$ of the accidents with victims in the whole period 2006-2011. This shows that, in spite of the segregation from motorised traffic, most bicycle accidents are still collisions with motor vehicles. Pedestrians were involved in a $7.1 \%$ of the accidents with victims in the same period. Both results are in sharp contrast with the results of the aforementioned survey of November 2011 [15]: $42 \%$ of respondents mentioned conflicts with pedestrians as the main source of safety problems when riding his bikes, while only a $20 \%$ mentioned conflicts with motorised vehicles. It could happen that the segregation of the bike paths from the motorised traffic had created a lower perception of risk regarding motor vehicles, while increasing the proximity between cyclists and pedestrians. This proximity may have incremented the perception of conflicts among cyclists and pedestrians, even though it was not associated to a substantial increase in the number of accidents. Other authors have also find out the presence of ideological or even political motivations in these perceptions [23].

\section{Future trends}

According the 2011 survey [15], the main demands of bicyclists on cycling infrastructure were on parking and other measures against thief $(36 \%)$, followed by improvements in the public bike system (28\%). Thus, the above mentioned lack of parking infrastructure seems to be a clear bottleneck for a further expansion of the bike use. The University of Sevilla has reacted to this demand by developing an ambitious and successful project for providing safe parking infrastructure inside his campuses [12]. Other main trip destinations, however, have not still developed similar policies. Thus parking at destination is a clear bottleneck, as well as parking at home (see previous section).

Using bikes in combination with public transport is an important aspect of cycling mobility in leading countries $[11,24,25]$. Table 4 shows the percentage of the different kind of urban train trips that combine with bicycle trips in the Metropolitan Area of Sevilla in 2009. These percentages are substantially higher for trips based on the city, a fact that probably reflects the existence of more cycling infrastructure (cycleways, parking and public bikes) in the city. However, they are still far from the percentages that are common in most cities of leading countries, like The Netherlands, Germany or Denmark [24]. 
Table 4: Percentage of trips using bicycles as an access and/or egress mode at the stations of urban trains in the Metropolitan Area of Sevilla during year 2009. Table compiled by the authors from data provided by the Agencia de Obra Pública de Andalucía - Junta de Andalucía.

\begin{tabular}{|l|c|c|c|c|}
\hline Trips/combinations & Bike-bike & Bike-other & Other-bike & Total \\
\hline Conurbation only & $1.14 \%$ & $0.49 \%$ & $1.05 \%$ & $2.67 \%$ \\
\hline Conurbation to city & $1.58 \%$ & $0.16 \%$ & $2.34 \%$ & $4.07 \%$ \\
\hline City only & $5.77 \%$ & $0.30 \%$ & $1.20 \%$ & $7.28 \%$ \\
\hline City to conurbation & $1.47 \%$ & $1.72 \%$ & $0.38 \%$ & $3.57 \%$ \\
\hline Total & $2.32 \%$ & $0.81 \%$ & $1.28 \%$ & $4.42 \%$ \\
\hline
\end{tabular}

Most of combined bike and train trips use bicycles as an access and egress mode (the bike-bike column in Table 4), which suggest that most cyclists chose a "bike on board" schema for these trips. Probably, this is a consequence of the aforementioned lack of parking infrastructure inside stations. It seems quite obvious that, in order to fully develop the intermodality between bicycles and public transports, it is necessary to shift from a "bike on board" concept to a "bike and ride" one $[24,25]$, by providing safe parking infrastructure inside the stations [11]. The regional government has reacted to this situation by developing a research project, aimed to improve intermodality between bikes and public transportation, as a way to promote both the cycling as the public transport in the whole metropolitan area [26]. This project is, in fact, a part of a more ambitious masterplan aimed to the promotion of cycling in the region [27].

We have also investigated the potential effect of a compulsory helmet regulation on the use of the bike in the city. This research was motivated by the recent announcement of this possibility by the Spanish Government. It has been reported that compulsory helmets can result in a decrease in the number of cyclist $[28,29]$, specifically in public bike schemas [30]. In order to confirm and estimate this potential decline in the number of bicyclists in Sevilla, we conducted a survey over 527 cyclists (344 on private bikes and 183 on public bikes) on 13 representative points of the cycle network along November and December of 2013. We asked how the effect of a hypothetical compulsory helmet regulation would affect their use of the bike. Specifically we asked about three possibilities:

- A lot: I will practically stop using the bike.

- Quite: I will use the bike substantially less.

- Not at all: I will continue using the bike in a similar way.

The results of this survey are shown in Figure 3. The columns for private and public bike users are direct results, while the results for all bikes are weighted by their actual percentages of use $(70 \%-30 \%$ approximately $[15,20])$. As it can be seen, a strong discouraging effect on the use of the bike has been detected. As expected, this effect is substantially higher for public bikes, a fact that has been probably driven the final decision of the Spanish Government of making helmets compulsory in urban areas just for kids under 16 . 


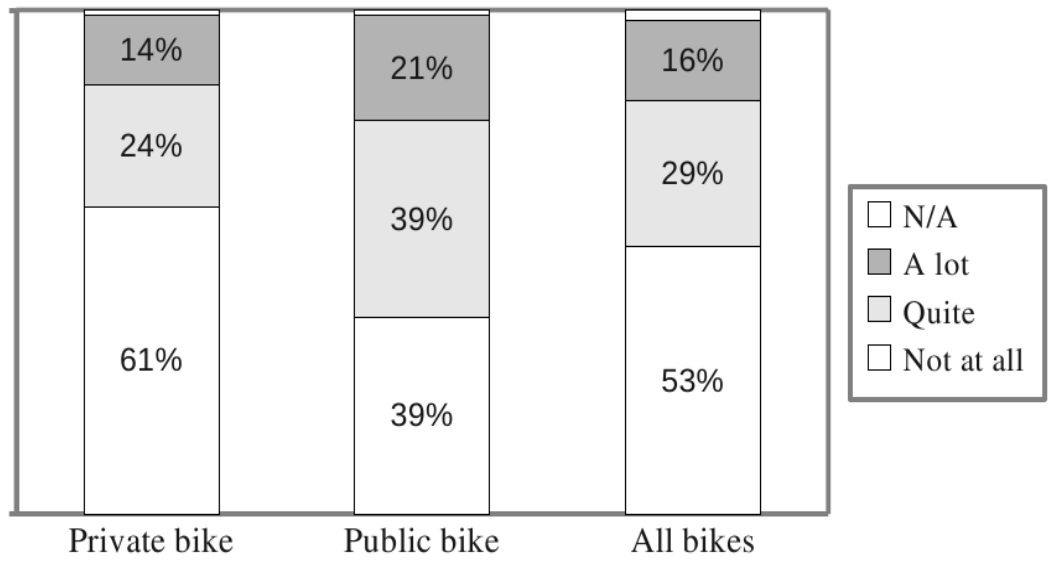

Figure 3: Perception of the impact on bicycle use of compulsory helmets by cyclists riding on private bikes, public bikes and all bikes. Compiled by the authors from the results of a survey made in Nov-Dec, 2013.

Respondents were also asked to give their opinion on this hypothetical compulsory helmet regulation. Most of them (61\% of private bike users and $64 \%$ of public bike users) were against this regulation. A $32 \%$ of private bike users and a $23 \%$ of public bike users supported this kind of regulation. We feel that the aforementioned results, altogether with the positive evolution of bicycle traffic accidents after the implementation of the network of cycleways, introduce doubts about the opportunity of this kind of regulation, at least in a city like Sevilla.

\section{Conclusions}

The experience of Sevilla shows how fast building of a network of segregated cycleways, designed in order to make cycling not just safe, but also easy and comfortable for everybody, can substantially increase the use of the bike even in cities without previous tradition of utilitarian cycling. In the case of Sevilla, the usage of the bike was multiplied by a factor of approximately 6 in just five years.

There also was an improvement in the combined use of the bike and public transport, in spite of the lack of appropriate parking infrastructures at the stations. In fact, parking infrastructures and other services for avoiding theft seem to be the main demand of cyclists and the most apparent bottleneck for further developments of bike mobility.

The implementation of the cycle network and the subsequent increase in the use of the bike was accompanied by an increase in the number of traffic accidents involving cyclists. However, this increase was not linear, and the number of accidents per bicycle trip fell by a significant amount, in agreement with the "safety in numbers" hypothesis. Cycling in Sevilla was more than three times safer in 2011 than in 2006. 
The segregation of bicyclist from motorised traffic seem to have shifted the perception of risk of cyclists from motor vehicles to pedestrians, even though motor vehicles still are by far the main cause of bicycle traffic accidents. This effect can be a consequence of the specific design of the cycleways that brings the cyclists closer to pedestrians. However, ideological factors seem to have also influenced this perception, and more specific research is necessary in order to elucidate this question.

We also have investigated the possible impact of a hypothetical compulsory helmet regulation on the use of the bike in the city of Sevilla. A meaningful impact has been detected, mainly over the public bike system. This fact, altogether with the positive evolution of bicycle traffic accidents after the implementation of the network of cycleways, introduces doubts about the suitability of this kind of regulation.

Our research has shown that, after the first burst of cycling in the period 2006-2011, the use of the bike seem now to be stabilized. Therefore, future trends to further improve bicycle mobility in the city have been also investigated. Lack of bicycle parking facilities at home and at final destinations, as well as the scarce intermodality between bike and public transportation seem now to be the main bottlenecks for a further expansion of bicycle mobility.

\section{Acknowledgements}

This work has been supported by the Agencia de Obra Pública de Andalucia Junta de Andalucía under Project G-GI3001/IDID. We would also like to thank the Ayuntamiento de Sevilla and the Dirección General de Tráfico for kindly providing many data for this analysis.

\section{References}

[1] National policies to promote cycling. European Conference of Ministers of Transport (EUCMT), Lubjana 2004. OECD. Online: http://internationaltransportforum.org/pub/pdf/04Cycling.pdf

[2] Pucher, J. Dill, J. \& Handy, S., Infrastructure, programs, and policies to increase bicycling: An international review Preventive Medicine, 50, pp. S106-S125, 2010.

[3] Pucher, J. \& Buehler, R., Making Cycling Irresistible: Lessons from the Netherlands, Denmark, and Germany. Transport Reviews, 28, pp. 495-528, 2008.

[4] De Boom, A., Walker, R., \& Goldup R., Shanghai: The greatest cycling city in the world? World Transport Policy \& Practice, 7, pp. 53-59, 2001.

[5] Shaheen, S., Zhang, H., Elliot, M. \& Guzman, S., (2011). Hangzhou Public Bicycle: Understanding Early Adoption and Behavioural Response to Bikesharing in Hangzhou, China. Transportation Research Record, 2247, pp. 34-41, 2011. 
[6] Pucher, J., Lanversin, E., Suzuki, T. \& Whitelegg, J., Cycling in Megacities: London, Paris, New York and Tokyo (Chapter 14) City Cycling eds J. Pucher and R. Buehler, pp 319-345. MIT Press, Cambridge MA, 2012.

[7] The Copenhagenize index 2013 of bicycle friendly cities. Copenhagenize Design Co. http://copenhagenize.eu/index/about.html

[8] Marques, R., Sevilla: Una experiencia exitosa de promoción de la movilidad en bicicleta en el Sur de Europa. Hábitat y Sociedad, 3, pp. 107-130, 2011. www.habitatysociedad.us.es

[9] TEMS - The EPOMM Modal Split Tool, European Platform on Mobility Management. http://epomm.eu/tems/index.phtml

[10] Tipología de las Vías Ciclistas. Ayuntamiento de Sevilla. Online: http://www.sevilla.org/sevillaenbici/Pdf/tipologia_vias_ciclistas.pdf

[11] CROW. Design manual for bicycle traffic. Netherlands: National Information and Technology Platform for Infrastructure, Traffic, Transport, and Public Space, 2006.

[12] La bicicleta en la Universidad de Sevilla (2012-2013). Sistema Integral de la Bicicleta de la Universidad de Sevilla (SIBUS). Online: http://bicicletas.us.es/?wpfb_dl=13

[13] Evaluación Sevici - Año 2013. Ayuntamiento de Sevilla - Gerencia de Urbanismo. Online: http://www.sevilla.org/sevillaenbici/Contenidos/1enbici/SEVICI-Balance2013.pdf

[14] Castillo-Manzano, J.I. \& Sanchez-Braza A., Managing a smart bicycle system when demand outstrips supply: the case of the university community in Sevilla Transportation, 40, pp. 459-477, 2013.

[15] Estudio sobre el uso de la bicicleta en Sevilla, 2011. Sistema Integral de la Bicicleta de la Universidad de Sevilla (SIBUS). Online: http://bicicletas.us.es/?wpfb_dl=20

[16] Encuesta domiciliaria de movilidad 2007. Database provided by Consorcio de Transportes del Área de Sevilla.

[17] Intensidades medias diarias. Centro de control de tráfico. Ayuntamiento de Sevilla: http://www.trajano.com/imd.html

[18] Plan de Transporte Metropolitano del Área de Sevilla: Plan de Movilidad Sostenible. Junta de Andalucía, Consejería de Obras Públicas: www.juntadeandalucia.es/servicios/planes/detalle/11689.html

[19] Estudio sobre el uso de la bicicleta en la ciudad de Sevilla - Enero 2010. Ayuntamiento de Sevilla http://www.consorciotransportes-sevilla.com/ proyectos/busbici/pdf/estudio_uso_bicicleta_sevilla_2010.pdf

[20] Evaluación del uso de la bicicleta en la ciudad de Sevilla, noviembre de 2013, Sistema Integral de la Bicicleta de la Universidad de Sevilla (SIBUS). http://bicicletas.us.es/?wpfb_dl=21

[21] Jacobsen P.L., Safety in numbers: more walkers and bicyclists, safer walking and bicycling. Injury Prevention, 9, pp. 205-209, 2003.

[22] Elvik, R., The non-linearity of risk and the promotion of environmentally sustainable transport. Accident Analysis \& Prevention. 41(4), pp. 849-855, 2009. 
[23] Castillo-Manzano, J.I. \& Sanchez-Braza A. Can anyone hate the bicycle? The hunt for an optimal local transportation policy to encourage bicycle usage. Environmental Politics, 22(6), pp. 1010-1028. 2013.

[24] Martens, K., The bicycle as a feedering mode: experiences from three European countries Transportation Research Part D, 9, pp. 281-294, 2004.

[25] Martens, K., Promoting bike-and-ride: The Dutch experience. Transportation Research Part A, 41, pp. 326-338, 2007.

[26] V. Hernández-Herrador, R. Marqués, Manuel Calvo-Salazar. Manuel López-Peña, Javier Herrera-Sánchez, Jesús Racero \& Leandro del Moral. Hacia un sistema intermodal bicicleta - transporte público. El caso de Sevilla. Proc. del XI Congreso de Ingeniería del Transporte. Santander (España), 9-11 June 2014.

[27] Plan Andaluz de la Bicicleta. Agencia de Obra Pública de la Junta de Andalucía. www.aopandalucia.es/planandaluzdelabicicleta/

[28] Robinson, D. L., No clear evidence from countries that have enforced the wearing of helmets. BMJ: British Medical Journal, 332(7543), pp. 722-725, 2006.

[29] De Jong, P., The health impact of mandatory bicycle helmet laws. Risk Analysis, 32(5), pp. 782-790, 2012.

[30] Fishman E., Washington S. \& Haworth N., Barriers and facilitators to public bicycle scheme use: A qualitative approach. Transportation Research Part F, 15, pp. 686-698, 2012. 